\title{
Toward Better Applied Math Placement for Engineering Students
}

\section{Stacie Pisano, University of Virginia}

After receiving a Master of Science in Electrical Engineering from Stanford University, Stacie Pisano worked as an Electrical Engineer and Technical Manager at AT\&T and Lucent Technologies Bell Laboratories for 16 years, designing and developing telecommunications equipment for the business market. After moving to Charlottesville, VA, she had the opportunity to teach Multivariable Calculus for UVA SEAS, and she was hooked. She has been teaching Applied Math from that point on and enjoying every minute.

\section{Prof. Bernard Fulgham, University of Virginia}

Bernard Fulgham received his PhD in Mathematics in 2002, writing his thesis in the field of non-associative algebras with advisor Kevin McCrimmon. He began teaching Applied Mathematics at the University of Virginia in August 2004 and was hired as an assistant professor in 2006. 


\section{Toward Better Applied Math Placement for Engineering Students}

\section{Introduction}

When students are empowered to make their own choices, how can they be persuaded to make a better choice?

At our institution, the engineering curriculum assumes that incoming students have already successfully completed Single Variable Calculus I in high school. For this reason, students are generally expected to take Single Variable Calculus II (or beyond) in their first semester. In reality, although most of our students have taken Calculus I in high school, there are many students who have not mastered Calculus I sufficiently to take Calculus II as their first college course. Until our efforts to create one, our institution was not offering a placement test to identify students who were insufficiently prepared for Calculus II.

Most placement tests that are currently available are focused on assessing Calculus readiness in general rather than readiness for Calculus II specifically. This includes ACT Compass and College Board Accuplacer, which are primarily designed to determine whether a student is ready for college-level mathematics, rather than for calculus placement. The highest level of Assessment and Learning in Knowledge Spaces (ALEKS) is pre-calculus. The MAA Maplesoft Placement Testing Suite offers both Calculus Readiness and Calculus Concept Readiness Tests, but no distinction between Calculus I and Calculus II or Multivariable Calculus. In addition, both Texas A\&M and the New Jersey Institute of Technology use math placement tests, but these tests are focused on determining proficiency in pre-calculus because they are only interested in evaluating readiness for Calculus I. See [1], [2], [3].

Hsu and Bressoud [4] reported on placement policies and strategies across a variety of institutions. As a $\mathrm{PhD}$ granting institution with below median full-time equivalent enrollment (approximately 2800 engineering undergraduates), our new policy and strategy lines up with similar institutions in their report (non-mandatory placement, department creation of test). Our institution is unusual in that applied mathematics including calculus is taught within the engineering school and not by the university's mathematics department. Therefore, our placement test can focus on those concepts and skills that are most needed by engineering students.

This paper reports on the development and implementation of a calculus placement test strategy for engineering students as well as the results obtained and further plans.

\section{Objectives}

Our project was to create and deliver a placement test system that would achieve the following goals and requirements:

1) Is free to students with no added direct costs to the institution.

2) Is fool-proof enough that students may successfully take a scheduled and timed test from home before the first semester. 
3) Collects calculus background information like high school courses, grades, and AP test scores.

4) Assesses students' current abilities in Pre-Calculus, Single Variable Calculus I, and Single Variable Calculus II.

5) Includes an algorithm to provide personalized placement recommendations to students based on both their reported calculus background and on the results of the assessment.

6) Includes a process to identify students who have improperly self-placed.

7) Provides students with access to advisors regarding placement recommendations.

8) Tracks and links placement test results and recommendations to final exam results from the first semester to assess the quality of the recommendations.

9) Includes improvements to test questions and to the placement algorithm to improve matching in future years.

\section{Results}

Delivery of Placement Test System

The placement test system was delivered in Summer 2018. The institution would not permit placement testing during summer orientation, and students were not assigned their computing IDs until summer orientation. Therefore, the placement test system was administered during the summer but after the rolling summer orientation sessions during which initial course enrollment took place. This is not ideal. As Mathematical Association of America (2010) recommends, it is best to provide the placement before students enroll in courses. We hope to make this improvement in future years.

Students were requested to register for the test via a Qualtrics Survey which collected background information, including self-reported AP scores and dual enrollment credits. Students could select from 3 testing sessions per day, 5 days per week. They were requested to register for a test time during a particular week following their summer orientation session, but alternatives were offered to those who needed or preferred to take the test during a different week.

WeBWorK [5] was used for the actual online placement test. WeBWorK is an open-source online homework system for math and science courses that is supported by the MAA and the NSF. The test consisted of multiple-choice questions with a focus on conceptual understanding.

In an effort to maintain security, the test questions will not be made available publicly. Still, there is a possibility of compromise due to student misconduct. This is minimized by limiting students to a registered time to take the test, limiting the time allowed to complete the test, and randomizing the answer order. Also, the incentive for misconduct is limited because test results are not binding. In addition, our students are subject to an honor code.

Students were provided their recommended placement by email and were offered further advice from Applied Math faculty. 
Compliance Rate

Although the placement test was "required" of all first-year students, there was no mechanism by which to penalize students who "opted" not to take the test.

There were 656 first-year students enrolled in an Applied Math course in Fall 2018. Of these, 38 had registered through Qualtrics but did not take the placement test. In addition, there were 132 students who neither registered nor took the placement test. Therefore, the compliance rate was $74.1 \%$.

There were 4 students who participated in the placement test system but did not complete their final exam. The data for these students is excluded from the average scores in the following sections.

Placement Test Content and Average Scores

The Placement Test consisted of 60 multiple choice questions. The average score was $61.8 \%$.

The levels and average performance were as follows:

\begin{tabular}{|l|c|c|}
\hline Level & Number of Questions & Average Score (\%) \\
\hline Pre-Calculus & 30 & 66.8 \\
\hline Single Variable Calculus I & 15 & 70.5 \\
\hline Single Variable Calculus II & 15 & 43.3 \\
\hline
\end{tabular}

Pre-Calculus test questions were categorized as follows, with some questions included in more than one category:

\begin{tabular}{|l|c|c|}
\hline Category & Number of Questions & Average Score (\%) \\
\hline Trigonometry & 14 & 67.4 \\
\hline $\begin{array}{l}\text { Logarithm/ Exponential } \\
\text { Functions }\end{array}$ & 10 & 61.5 \\
\hline Simplifying Expressions & 5 & 63.2 \\
\hline Solving Equations & 5 & 60.7 \\
\hline Limits & 5 & 59.9 \\
\hline Graphing & 5 & 80.1 \\
\hline
\end{tabular}

Placement Recommendations

The algorithm for recommending placement is shown in Appendix 1 - Placement Test Algorithm.

Here are a few important points: 
- Many of our students struggle with Pre-Calculus as much as, if not more than, with Calculus. Therefore, we consider passing both the Pre-calculus and Calculus I portions of the placement test to be the gateway to Calculus II. We did allow scoring a 5 on the AP $\mathrm{AB}$ exam to override the placement test results for Pre-Calculus and Calculus I.

- Similarly, scoring a 5 on the AP BC exam conveys credit for Calculus II and overrides the placement test results for Calculus II. Actual recommendations were made based on self-reported AP BC scores. These might not be accurate due to the timing of the data collection process.

- Our institution does not grant transfer credit of any kind for Calculus I.

- Dual enrollment credit did not override the placement test results in the recommendation decision.

- Students without Calculus II credit must take Calculus II, regardless of the placement test results.

- The placement algorithm produced recommendations for students. These recommendations were not binding.

- The placement test did not test Multivariable Calculus topics, so recommendations beyond Multivariable Calculus are based solely on reported transfer/dual enrollment credits.

- For each of the placement test sections, Pre-Calculus, Calculus I, and Calculus II, a passing score was considered to be $60 \%$ or more.

\section{Student Results by Course}

Below are the final exam score average and Calculus grade point average (GPA) for students according to whether the student placed themselves below recommendation (UNDER), at recommendation (AT), or above recommendation (OVER) according to the placement algorithm. The Final Exam score used is the number of standard deviations above $(+)$ or below (-) the mean, $z=\frac{x-\bar{x}}{s}$. The GPA is calculated according to the table in Appendix 2 - Grade Point Average Assignment.

\section{Calculus I Results}

In Calculus I, no students are considered to be placed over the algorithm placement because all of our students must take at least Calculus I in the first year. Only one student who met the criteria to be placed above Calculus I instead chose to take Calculus I. 


\begin{tabular}{|l|r|r|r|}
\hline \multicolumn{4}{|c|}{ Calculus I Results } \\
\hline & $\begin{array}{l}\text { Final } \\
\text { Exam } \\
\text { z-score }\end{array}$ & GPA & Count \\
\hline UNDER & 0.024 & 4.00 & 1 \\
\hline AT & 0.072 & 2.95 & 61 \\
\hline OVER & & & \\
\hline $\begin{array}{l}\text { No Placement } \\
\text { Test }\end{array}$ & -0.219 & 2.85 & 24 \\
\hline
\end{tabular}

Note that the students who chose not to take the placement test scored lower than those who did take the placement test in both the final exam and GPA.

Results shown here are based on self-reported AP AB scores which might not be accurate due to the timing of the data collection process. Credit is not given for Calculus I so there is no record of actual AP AB scores.

\section{Calculus II Results}

Results shown here are based on actual AP BC scores and actual transfer/dual enrollment credit as recorded by the registrar. These may differ from the self-reported AP BC scores and transfer/dual enrollment credits on which the actual recommendations were made.

\begin{tabular}{|l|r|r|r|}
\hline \multicolumn{4}{|c|}{ Calculus II Results } \\
\hline & $\begin{array}{l}\text { Final } \\
\text { Exam } \\
\text { z-score }\end{array}$ & GPA & \multicolumn{1}{c|}{ Count } \\
\hline Placement & 0.021 & 3.67 & 3 \\
\hline ATDER & 0.263 & 3.44 & 135 \\
\hline OVER & -0.386 & 2.58 & 48 \\
\hline $\begin{array}{l}\text { No Placement } \\
\text { Test }\end{array}$ & -0.368 & 2.83 & 55 \\
\hline
\end{tabular}

Note that the results for students who chose not to take the placement test are similar to the results for students who placed themselves higher than the algorithm placement.

\section{Multivariable Calculus Results}

Results shown here are based on actual AP BC scores and actual transfer/dual enrollment credit as recorded by the registrar. These may differ from the self-reported AP BC scores and transfer/dual enrollment credits on which the actual recommendations were made. 
No students are considered to be placed under the algorithm-recommended placement because the placement test did not assess Multivariable Calculus.

\begin{tabular}{|l|r|r|r|}
\hline \multicolumn{4}{|c|}{ Multivariable Calculus Results } \\
\hline & $\begin{array}{l}\text { Final } \\
\text { Exam } \\
\text { z-score }\end{array}$ & GPA & Count \\
\hline UNDER & & & \\
\hline AT & 0.228 & 3.45 & 146 \\
\hline OVER & -0.279 & 2.91 & 14 \\
\hline $\begin{array}{l}\text { No Placement } \\
\text { Test }\end{array}$ & 0.082 & 2.76 & 65 \\
\hline
\end{tabular}

Honors Engineering Math I Results

Honors Engineering Math (HEM) is a two-course sequence that provides students with an enhanced Calculus experience. Students who place into Multivariable Calculus may opt to take the HEM sequence instead. HEM I counts as an elective while HEM II, which these students will take in the Spring, fulfills their Multivariable Calculus requirement.

\begin{tabular}{|l|r|r|r|}
\hline \multicolumn{4}{|c|}{ HEM I Results } \\
\hline & $\begin{array}{l}\text { Final } \\
\text { Exam } \\
\text { z-score }\end{array}$ & GPA & Count \\
\hline UNDER & & & \\
\hline AT & 0.095 & 3.46 & 19 \\
\hline OVER & 0.568 & 3.30 & 1 \\
\hline $\begin{array}{l}\text { No Placement } \\
\text { Test }\end{array}$ & -0.475 & 3.20 & 5 \\
\hline
\end{tabular}

\section{Enrollment Stability}

Of the 62 Calculus I students who participated in the placement process, 17 students had enrolled in Single Variable Calculus I before the placement test. Thirty-nine more students enrolled after the placement test but before the beginning of the semester, generally moving from Single Variable Calculus II. Then 6 more students switched from Single Variable Calculus II after the beginning of the semester. In the past, we usually experienced a migration of 2 to 3 dozen students from Single Variable Calculus II to Single Variable Calculus I after the beginning of the Fall semester. One of the effects of the placement test process was to reduce this churn, which is disruptive to both students and faculty.

Of the 186 Calculus II students who participated in the placement process, 183 students were enrolled in Calculus II at the beginning of the semester. Two students switched in from Calculus 
I after the semester began and one switched in from Differential Equations, most likely to obtain necessary credit.

Of the 160 Multivariable Calculus students who participated in the placement process, 158 students were enrolled in Multivariable Calculus at the beginning of the semester. Two students switched in from Honors Engineering Math I after the semester began. Honors Engineering Math $\mathrm{I}$ is at the same level in the placement algorithm.

Of the 20 Honors Engineering Math I students who participated in the placement process, all were enrolled prior to the beginning of the semester.

In the following table, Participating Students are first-year students who completed the placement test. Initial Enrollment is the count of students enrolled at each level prior to the placement test. Pre-semester Enrollment is the count of students enrolled at each level on the first day of class. Final Enrollment is the count of students enrolled at the conclusion of the semester.

\begin{tabular}{|l|c|c|c|c|}
\hline Participating Students & $\begin{array}{l}\text { Single Variable } \\
\text { Calculus I }\end{array}$ & $\begin{array}{l}\text { Single Variable } \\
\text { Calculus II }\end{array}$ & $\begin{array}{l}\text { Multivariable } \\
\text { Calculus }\end{array}$ & HEM I \\
\hline Initial Enrollment & 17 & 176 & 148 & 19 \\
\hline $\begin{array}{l}\text { Pre-Semester } \\
\text { Enrollment }\end{array}$ & 56 & 183 & 158 & 20 \\
\hline Final Enrollment & 62 & 186 & 160 & 20 \\
\hline
\end{tabular}

Placement Test vs. AP BC Results in Multivariable Calculus

In order to assess whether the Placement Test provides useful information beyond that provided by AP BC test results, the data was further analyzed. In the following table, AP1 designates the students who passed the AP BC exam (score of 5), and AP0 designates the students who did not pass the AP BC exam. Also, PT1 designates the students who passed the Calculus II portion of the Placement Test, and PT0 designates the students who did not pass the Calculus II portion of the Placement Test. Participating students are those who participated in the placement test system.

\begin{tabular}{|l|c|r|r|}
\hline \multicolumn{4}{|c|}{ Multivariable Calculus Results } \\
\hline & $\begin{array}{l}\text { Final } \\
\text { Exam } \\
\text { z-score }\end{array}$ & GPA & Count \\
\hline Participating AP1 PT1 & 0.4027 & 3.66 & 66 \\
\hline Participating AP1 PT0 & 0.0780 & 3.29 & 76 \\
\hline Participating AP0 PT1 & 0.1321 & 3.06 & 5 \\
\hline Participating AP0 PT0 & -0.2893 & 2.90 & 13 \\
\hline Not Participating AP1 & 0.2048 & 3.37 & 55 \\
\hline Not Participating AP0 & -0.5966 & 2.61 & 10 \\
\hline
\end{tabular}


Passing the Calculus II portion of the placement test does seem to signal better performance in Multivariable Calculus whether or not a student has passed the AP BC exam.

The following table compares results for Multivariable Calculus students who obtained their Calculus II credit through passing the AP BC exam (score of 5) and students who obtained their Calculus II credit through transfer credit. In most cases, transfer credit is dual-enrollment credit. Also included are 9 students who enrolled in Multivariable Calculus without Calculus II credit, which is not supposed to be permitted. One student earned both AP and transfer credit. For that student, only the transfer credit will be applied.

\begin{tabular}{|l|c|r|r|}
\hline \multicolumn{3}{|c|}{ Multivariable Calculus Results } \\
\hline & $\begin{array}{l}\text { Final } \\
\text { Exam } \\
\text { Calculus II credit }\end{array}$ & $\begin{array}{l}\text { GPA } \\
\text { z-score }\end{array}$ & Count \\
\hline AP BC & 0.2222 & 3.43 & 197 \\
\hline $\begin{array}{l}\text { Transfer (Dual- } \\
\text { enrollment) }\end{array}$ & -0.2651 & 2.92 & 20 \\
\hline None & -0.3610 & 2.74 & 9 \\
\hline
\end{tabular}

\section{Summary}

In general, students who placed themselves at or below the algorithm-recommended placement performed better on both the final exam and in the final letter grade (GPA) than students who placed themselves above the recommended placement.

In general, students who did not participate in the placement process performed poorly relative to students who did participate.

The placement test appears be an improvement over a recommendation based solely on AP BC exam results. This is especially important for students who do not take the AP BC exam.

One of the primary benefits of this placement process was to shift more students toward a recommended placement before the semester began, reducing the churn that has been typical.

\section{Further Study}

Hsu and Bressoud [4] recommend that locally developed placement tests and strategies such as ours undergo continuous improvement based on local data. Our results will be examined to improve the placement test by modifying the questions that were least predictive or that have a low discrimination index.

Incoming first-years will be briefed on the results to encourage them to participate in the placement process and to follow the recommendation. 
Going forward, we hope to be able to administer the placement test and provide a recommendation before students initially enroll in courses. This would certainly be more efficient for students and faculty alike. 


\section{References}

[1] Mathematical Association of America (2010). Placement Test Program User's Guide.

Retrieved March 16, 2019 from www.maa.org/sites/default/files/pdf/ptp/ptpguide.pdf.

[2] M. Pilant, R. Hall, and E. Jung (2012), “Comprehensive Statistical Analysis of a Mathematics Placement Test." In Society for Information Technology \& Teacher Education International Conference, 4432-4439, Association for the Advancement of Computing in Education (AACE).

[3] A. Borgaonkar, J. Sodhi, M. Kam, and E. Hou (2018), "Impact of Initiatives for Helping First Year Students Start on Track in Mathematics Sequence.” In 2018 ASEE Annual Conference \& Exposition, Salt Lake City, Utah. https://peer.asee.org/30602.

[4] E. Hsu and D. Bressoud (2015), "Placement and student performance in Calculus I." Insights and Recommendations from the MAA National Study of College Calculus, MAA Notes, 59-67. Retrieved March 15, 2019 from https://www.maa.org/sites/default/files/pdf/cspcc/InsightsandRecommendations.pdf

[5] "Welcome to WeBWorK", Mathematical Association of America. http://webwork.maa.org/. 


\section{Appendix 1 - Placement Algorithm Flowchart}

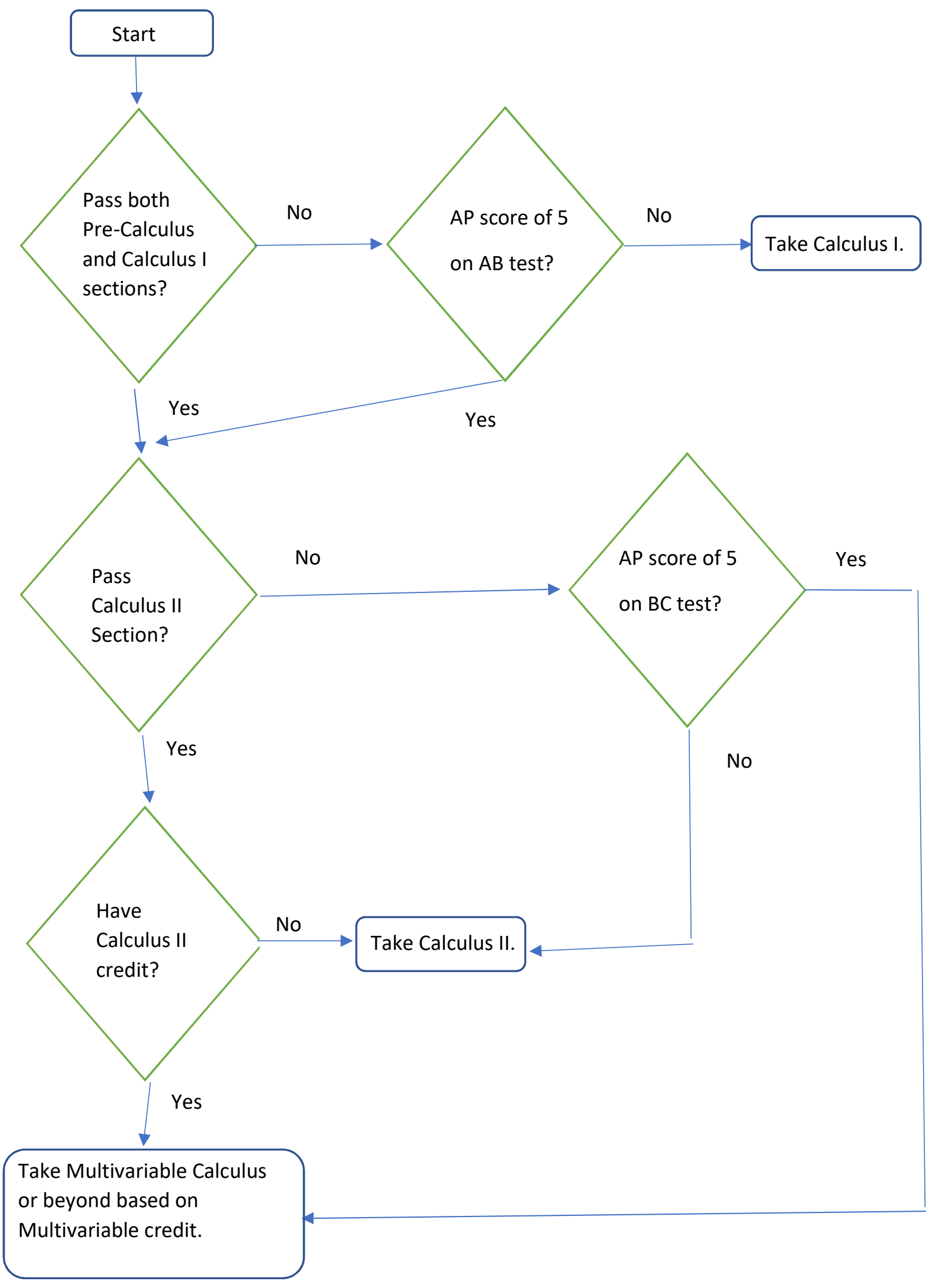


Appendix 2 - Grade Point Average Assignment

\begin{tabular}{|l|l|}
\hline Letter Grade & GPA \\
\hline A + & 4.3 \\
\hline A & 4.0 \\
\hline A- & 3.7 \\
\hline B + & 3.3 \\
\hline B & 3.0 \\
\hline B- & 2.7 \\
\hline C + & 2.3 \\
\hline C & 2.0 \\
\hline C- & 1.7 \\
\hline D + & 1.3 \\
\hline D & 1.0 \\
\hline D- & 0.7 \\
\hline
\end{tabular}

